\title{
LA POLITIQUE
}

ET LE COMMERCE FRANÇAIS

DANS LE

GOLFE DE GUINÉE

de 1838 à I 871 
ÉCOLE PRATIQUE DES HAUTES ÉTUDES - SORBONNE VI SECTION : SCIENCES ECONOMIQUES ET SOCIALES

\section{LE MONDE D'OUTRE-MER PASSÉ ET PRÉSENT}

PREMIËRE SÉRIE

\section{ÉTUDES}

\section{$\mathrm{XI}$}




\section{BERNARD SCHNAPPER}

\section{LA POLITIQUE \\ ET LE COMMERCE FRANÇAIS \\ DANS LE \\ GOLFE DE GUINÉE \\ de I838 à I87I}

PARIS MOUTON \& CO LA HAYE MCMLXI 
(9) I96I, Mouton \& Co, Publishers, Paris - The Hague. 